\title{
Error propagation approach for estimating root mean square error of the reference evapotranspiration when estimated with alternative data
}

\author{
Homayoon Ganji, Takamitsu Kajisa \\ Graduate School of Bioresources, Mie University, Tsu City, Mie, Japan
}

\begin{abstract}
Estimation of reference evapotranspiration $\left(E T_{0}\right)$ with the Food and Agricultural Organisation (FAO) Penman-Monteith model requires temperature, relative humidity, solar radiation, and wind speed data. The lack of availability of the complete data set at some meteorological stations is a severe restriction for the application of this model. To overcome this problem, ET 0 can be calculated using alternative data, which can be obtained via procedures proposed in FAO paper No.56. To confirm the validity of reference evapotranspiration calculated using alternative data $\left(E T_{0}(\mathrm{Alt})\right)$, the root mean square error (RMSE) needs to be estimated; lower values of $R M S E$ indicate better validity. However, $R M S E$ does not explain the mechanism of error formation in a model equation; explaining the mechanism of error formation is useful for future model improvement. Furthermore, for calculating $R M S E, E T_{0}$ calculations based on both complete and alternative data are necessary. An error propagation approach was introduced in this study both for estimating RMSE and for explaining the mechanism of error formation by using data from a 30 -year period from 48 different locations in Japan. From the results, RMSE was
\end{abstract}

Correspondence: Homayoon Ganji, Graduate School of Bioresources, Mie University, 1577 Kurimamachiya-cho, Tsu City, Mie 514-8507, Japan.

Tel.: +81.59.231.9581- Fax: +81.59.231.9581.

E-mail: homayonganji@gmail.com

Key words: Error propagation approach; root mean square error; reference evapotranspiration; alternative data.

Contributions: the authors contributed equally.

Conflict of interests: the authors declare no potential conflict of interests.

Conference presentation: the concept in this paper was presented at the PAWEES 2017 International Conference, Nov. 9-10, Taiwan.

Received for publication: 11 October 2018.

Accepted for publication: 24 April 2019.

CC Copyright: the Author(s), 2019

Licensee PAGEPress, Italy

Journal of Agricultural Engineering 2019; L:909

doi:10.4081/jae.2019.909

This article is distributed under the terms of the Creative Commons Attribution Noncommercial License (by-nc 4.0) which permits any noncommercial use, distribution, and reproduction in any medium, provided the original author(s) and source are credited. confirmed to be proportional to the value produced by the error propagation approach $\left(\triangle E T_{0}\right)$. Therefore, the error propagation

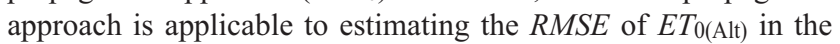
range of $12 \%$. Furthermore, the error of $E T_{0 \text { (Alt) }}$ is not only related to the variables' uncertainty but also to the combination of the variables in the equation.

\section{Introduction}

Reference evapotranspiration $\left(E T_{0}\right)$ is defined as a biophysical process whereby liquid water is vaporized into the atmosphere from a reference-evaporating surface. The reference surface is a hypothetical grass reference crop with an assumed $0.12 \mathrm{~m}$ crop height, a fixed $70 \mathrm{~s} \mathrm{~m}^{-1}$ surface resistance and an albedo of 0.23 (Allen et al., 1988). Many empirical equations have been reported in the literature for estimating $E T_{0}$ (Pereira and Pruitt, 2004; Alexandris et al., 2005). These empirical methods have been based mainly on climatological data due to the difficulty of making direct $E T_{0}$ measurements. One of the most accurate methods currently available is the FAO-56 Penman-Monteith equation, known as FAO-56 PM in this study, which has been accepted as a standard method by the international scientific community (Chiew et al., 1995; Gavilán et al., 2006). However, to estimate $E T_{0}$ using FAO-56 PM, measured input data are required (Allen et al., 1998). The data required are the maximum and minimum temperature ( $T_{\max }$ and $\left.T_{\min }\right)$, relative humidity $(R H)$, solar radiation $\left(R_{\mathrm{s}}\right)$ and wind speed $\left(u_{2}\right)$. The lack of availability of the complete data set at some meteorological stations is a severe restriction for the application of this equation, as in the case in developing countries (Popova et al., 2006). Few weather stations are equipped to supply this complete set of weather variables (Droogers and Allen, 2002). To overcome the problem of the missing data, the FAO-56 PM

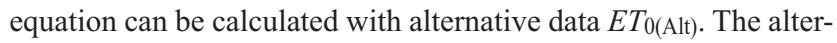
native data are data, which were not measured directly at the site, but can be estimated using the workarounds proposed in FAO paper No.56.

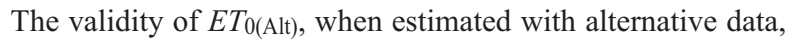
has been tested by several researchers in a variety of climate conditions worldwide, using statistical tools such as RMSE and regression analysis (Popova et al., 2006; Jabloun et al., 2008; Sentelhas et al., 2010; Cordova et al., 2015). For confirming the

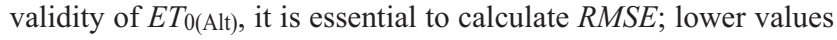
of RMSE indicate better validity. However, neither RMSE or the regression analysis specify the mechanism of error formation in the $E T_{0}$ model when estimating with alternative data. Specifying the mechanism of error formation in the $E T_{0}$ model when estimating with alternative data is very useful for application of the model in a given area. To examine the error formation in the model equation, the error propagation approach is one of the proper ways, as it is designed to specify the effect of the alternative data's uncer- 
tainty on the error of a function in order to provide an accurate estimation of a function's error. Therefore, our hypothesis are: i) the value of RMSE is proportional to the value given by error propagation approach when estimating $E T_{0}$ with alternative data; ii) the error of $E T_{0}$ when estimating with alternative data relates to, not only the alternative data, but to structure of the model (sensitivity of the model) as well.

In this study, the applicability of the theoretical error propagation approach was examined both for calculating RMSE and for specifying the mechanism of error formation in the model equation.

The objectives of this study are as follows: i) to compare standard $E T_{0(\mathrm{St})}$ and $E T_{0 \text { (Alt) }}$ for confirming the validity of alternative data in the $E T_{0}$ estimation; ii) to estimate $R M S E$ using error propagation approach; iii) to examine error propagating approach for specifying the mechanism of error formation in the $E T_{0}$ equation when estimating with alternate data.

\section{Materials and methods}

\section{Study site and meteorological data}

In this study, metrological data were obtained from the Automated Meteorological Data Acquisition System (AMeDAS), which is a collection of automatic weather stations (AWSs) run by the Japan Metrological Agency (JMA) for automatic observation of precipitation, wind direction and speed, temperature and sunshine duration to support real-time monitoring of weather conditions with high temporal and spatial resolution. JMA began operating the AMeDAS system at average intervals of $17 \mathrm{~km}$ nationwide. The data in this study correspond to 48 different locations in 45 prefectures of Japan over a 30-year period from 1988 to 2017. The study locations are numbered from 1-48 at Figure 1; the corresponding geographical coordinate points are listed at Table 1.

The measured meteorological variables $T, n, R H$ and $u_{2}$ are needed to estimate $E T_{0(\mathrm{St})}$. The average values of the measured metrological variables along with the estimated values of $R_{\mathrm{S}}$ and actual vapour pressure $\left(e_{\mathrm{a}}\right)$ for each location are listed at Table 1 .

\section{Calculation procedure}

The FAO-56 PM calculation was used with both sets of data, measured and alternative, in each location to assess the validity of

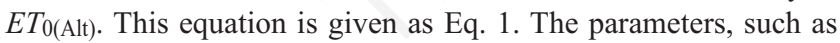
$R_{\mathrm{n}}, R_{\mathrm{s}}$, and $e_{\mathrm{a}}$, were calculated with measured climatic data using given as Eqs. 2-4:

$$
\begin{aligned}
& R_{s}=\left(0.23+0.50 \frac{n}{N}\right) R_{a} \\
& e_{a}=\frac{R H_{\text {mean }}}{100} e_{s}
\end{aligned}
$$$$
E T_{0(s t)}=\frac{0.408 \Delta\left(R_{n}-G\right)+\gamma \frac{900}{T_{A v e}+273} u_{2}\left(e_{s}-e_{a}\right)}{\Delta+\gamma\left(1+0.34 u_{2}\right)}
$$$$
R_{n}=(1-\alpha) R_{s}-\sigma \frac{T_{\max }+T_{\min }}{2}\left(0.34-0.14 \sqrt{e_{a}}\right)\left(1.35 \frac{R_{s}}{R_{s o}}-0.35\right)(2)
$$

where $E T_{0(\mathrm{St})}$ is the correct reference evapotranspiration calculated with measured climatological data $\left(\mathrm{mm} \mathrm{d}^{-1}\right)$, D is the slope of the vapour pressure curve $(\mathrm{kPa}), R_{\mathrm{n}}$ is the net radiation estimated with solar radiation data $\left(\mathrm{MJ} \mathrm{m}^{-2} \mathrm{~d}^{-1}\right), G$ is the soil heat flux $\left(\mathrm{MJ} \mathrm{m}^{-2} \mathrm{~d}^{-1}\right)$, $g$ is the psychrometric constant $\left(\mathrm{kPa}^{\circ} \mathrm{C}^{-1}\right), T_{\text {Ave }}$ is the daily average air temperature $\left({ }^{\circ} \mathrm{C}\right), u_{2}$ is the daily average wind speed $\left(\mathrm{m} \mathrm{s}^{-1}\right), e_{\mathrm{S}}$ is the saturation vapour pressure $(\mathrm{kPa}), e_{\mathrm{a}}$ is the actual vapour pressure $(\mathrm{kPa}), R_{\mathrm{S}}$ is the solar radiation $\left(\mathrm{MJ} \mathrm{m}^{-2} \mathrm{~d}^{-1}\right), a$ is the albedo (0.23), $\sigma$ is the Stefan-Boltzmann constant, $R_{\mathrm{SO}}$ is the clear-sky solar radiation $\left(\mathrm{MJ} \mathrm{m} \mathrm{m}^{-2} \mathrm{~d}^{-1}\right)$ and $R H_{\text {mean }}$ is the mean relative humidity $(\%)$.

According to the FAO methodology, Eq. 1 can be calculated with alternative data of solar radiation $\left(E T_{0(\mathrm{Rs})}\right)$, alternative actual vapour pressure $\left(E T_{0}\right.$ (ea) $)$ (relative humidity corresponds to actual vapour pressure in the FAO-56PM equation), and alternative wind speed $\left(E T_{0(\mathrm{u} 2)}\right)$. The procedures allowing alternative data to be estimated are described as follows:

Alternative solar radiation: Solar radiation records are used to estimate $R_{\mathrm{n}}$. When $R_{\mathrm{S}}$ based on hours of sunshine or directly measured data is missing, Hargreaves' radiation formula as a function of $T_{\max }$ and $T_{\min }$ is recommended to substitute for the missing data, Eq. 5. Hargreaves' radiation formula assumes that the difference between $T_{\max }$ and $T_{\min }$ is governed by the daily solar radiation (Hargreaves and Samani, 1985). It is abbreviated here in this study as $\left(R_{\mathrm{S}(\mathrm{Alt})}\right)$.

$$
R_{s(A l t)}=k_{R s} \sqrt{T_{\max }-T_{\min }} \times R_{a}
$$

where $R_{\mathrm{S}(\mathrm{Alt})}$ is the solar radiation based on temperature ( $\mathrm{MJ} \mathrm{m} \mathrm{m}^{-2} \mathrm{~d}^{-1}$ ), $T_{\max }$ is the maximum air temperature $\left({ }^{\circ} \mathrm{C}\right), T_{\min }$ is the minimum air temperature $\left({ }^{\circ} \mathrm{C}\right), R_{\mathrm{a}}$ is the extraterrestrial radiation $\left(\mathrm{MJ} \mathrm{m} \mathrm{m}^{-2} \mathrm{~d}^{-1}\right)$ and $k_{\mathrm{rs}}$ is the adjustment coefficient proposed by Allen et al. (1998) as 0.16 and 0.19 for interior and coastal areas, respectively $\left({ }^{\circ} \mathrm{C}^{-0.5}\right)$. In this study, $k_{\mathrm{rs}}=0.19$ was used for all locations since the air masses that dominate in all locations have their origin in the surrounding seawater.

Alternative relative humidity: Relative humidity is used to calculate actual vapour pressure $e_{\mathrm{a}}$. When $R H$ is missing $e_{\mathrm{a}}$ can be calculated on the assumption that $T_{\min }$ is close to dewpoint temperature $\left(T_{\text {dew }}\right)$, Eq. 6 . This should be useful in humid areas, where the difference between $T_{\min }$ and $T_{\text {dew }}$ is small. In arid areas, however, there is often a large difference between $T_{\min }$ and $T_{\text {dew }}$ (Kimbal et al., 1997).

$$
e_{a(A l t)}=0.6108 \times e^{\left(\frac{17.27 \times T_{\min }}{T_{\min }+273.3}\right)}
$$

where $e_{\mathrm{a}(\mathrm{Alt})}$ is the actual vapour pressure estimated using $T_{\min }$ $(\mathrm{kPa})$ and $T_{\min }$ is the minimum air temperature $\left({ }^{\circ} \mathrm{C}\right)$.

Alternative wind speed: Missing wind speed data can be recovered based on two alternative approaches, either the default world average value of wind speed, which is $2 \mathrm{~m} \mathrm{~s}^{-1}$, or the data from a nearby station can be used if available (Allen et al., 1998). In this study, the default world average value was used.

\section{Statistical analysis}

In accordance with earlier studies (Popova et al., 2006; Sentelhas et al., 2010; Cordova et al., 2015), regression analysis was used to assess the performance of $E T_{0 \text { (st) }}$ and $E T_{0 \text { (Alt). The }}$ slope of the regression $(b)$ was used as the measure of the accuracy, and the coefficient of determination $\left(R^{2}\right)$ was used as the measure of the exactness. The agreement between $E T_{0 \text { (st) }}$ and $E T_{0 \text { (Alt) was }}$ 
Table 1. Average record of the meteorological variables and estimated variables needed for calculating evapotranspiration.

\begin{tabular}{|c|c|c|c|c|c|c|c|c|c|}
\hline \multirow{2}{*}{$\begin{array}{l}\text { Station } \\
\text { number }\end{array}$} & \multirow[t]{2}{*}{ Station location } & \multicolumn{2}{|c|}{ Coordinate } & \multicolumn{3}{|c|}{ Measured variables } & \multirow[b]{2}{*}{$\begin{array}{l}R H \\
(\%)\end{array}$} & \multicolumn{2}{|c|}{ Estimated variables } \\
\hline & & $\begin{array}{c}\text { Elevation } \\
\text { (m) }\end{array}$ & $\begin{array}{l}\text { Latitude } \\
\text { (Degree) }\end{array}$ & $\begin{array}{l}n \\
\text { (h) }\end{array}$ & $\begin{array}{l}T_{\text {Ave }} \\
\left({ }^{\circ} \mathrm{C}\right)\end{array}$ & $\begin{array}{c}u_{2} \\
\left(\mathrm{~m} \mathrm{~s}^{-1}\right)\end{array}$ & & $\begin{array}{c}R_{S} \\
\left(\mathrm{MJ} \mathrm{m}^{-2} \mathrm{~d}^{-1}\right)\end{array}$ & $\begin{array}{c}e_{a} \\
(\mathrm{kPa})\end{array}$ \\
\hline 1 & Wakkanai & 3 & 45.41 & 4.0 & 7.1 & 3.0 & 75.3 & 11.1 & 0.29 \\
\hline 2 & Sapporo & 17 & 43.06 & 4.7 & 9.4 & 1.8 & 68.8 & 12.2 & 0.33 \\
\hline 3 & Kushiro & 5 & 42.98 & 5.3 & 6.6 & 2.5 & 76.8 & 12.3 & 0.28 \\
\hline 4 & Aomori & 3 & 40.82 & 4.3 & 10.9 & 2.3 & 74.6 & 12.2 & 0.45 \\
\hline 5 & Akita & 6 & 39.71 & 4.2 & 12.1 & 2.6 & 72.8 & 12.2 & 0.48 \\
\hline 6 & Morioka & 155 & 39.69 & 4.6 & 10.8 & 2.0 & 73.7 & 12.4 & 0.42 \\
\hline 7 & Sendai & 39 & 38.26 & 5.0 & 13.0 & 1.9 & 70.9 & 13.0 & 0.50 \\
\hline 8 & Yamagata & 290 & 38.25 & 4.4 & 12.4 & 1.3 & 73.8 & 12.6 & 0.55 \\
\hline 9 & Niigata & 0 & 37.89 & 4.5 & 14.3 & 2.4 & 71.3 & 12.9 & 0.58 \\
\hline 10 & Fukushima & 67 & 37.75 & 4.8 & 13.7 & 1.5 & 68.8 & 12.9 & 0.53 \\
\hline 11 & Toyama & 9 & 36.70 & 4.4 & 14.6 & 2.0 & 76.3 & 12.9 & 0.68 \\
\hline 12 & Kanazawa & 6 & 36.58 & 4.6 & 15.1 & 2.2 & 71.0 & 13.2 & 0.67 \\
\hline 13 & Utsunomiya & 119 & 36.54 & 5.3 & 14.6 & 1.7 & 69.4 & 13.5 & 0.55 \\
\hline 14 & Maebashi & 112 & 36.40 & 5.9 & 15.3 & 2.0 & 62.3 & 14.2 & 0.51 \\
\hline 15 & Matsumoto & 610 & 36.24 & 5.8 & 12.6 & 1.6 & 67.8 & 14.4 & 0.46 \\
\hline 16 & Kumagai & 30 & 36.15 & 5.7 & 15.7 & 1.7 & 64.7 & 14.1 & 0.55 \\
\hline 17 & Fukui & 9 & 36.05 & 4.5 & 15.1 & 1.8 & 74.8 & 13.1 & 0.70 \\
\hline 18 & Tokyo & 20 & 35.69 & 5.3 & 16.7 & 2.0 & 61.8 & 13.7 & 0.56 \\
\hline 19 & Kofu & 273 & 35.66 & 6.1 & 15.6 & 1.4 & 63.8 & 14.7 & 0.53 \\
\hline 20 & Chiba & 3 & 35.06 & 5.3 & 16.4 & 2.4 & 67.9 & 13.8 & 0.60 \\
\hline 21 & Tottori & 7 & 35.48 & 4.5 & 15.5 & 1.9 & 73.5 & 13.2 & 0.67 \\
\hline 22 & Matsue & 17 & 35.45 & 4.6 & 15.5 & 2.2 & 75.5 & 13.3 & 0.69 \\
\hline 23 & Yokohama & 39 & 35.43 & 5.5 & 16.5 & 2.4 & 66.7 & 14.1 & 0.58 \\
\hline 24 & Gifu & 13 & 35.40 & 5.7 & 16.4 & 1.7 & 66.3 & 14.5 & 0.63 \\
\hline 25 & Hikone & 87 & 35.27 & 5.0 & 15.2 & 1.9 & 73.8 & 13.8 & 0.66 \\
\hline 26 & Nagoya & 51 & 35.16 & 5.8 & 16.5 & 2.1 & 65.8 & 14.6 & 0.60 \\
\hline 27 & Kyoto & 36 & 35.01 & 4.8 & 16.5 & 1.3 & 65.6 & 13.4 & 0.63 \\
\hline 28 & Tsu & 2 & 34.73 & 5.7 & 16.5 & 2.8 & 67.8 & 14.5 & 0.60 \\
\hline 29 & Kobe & 3 & 34.69 & 5.5 & 17.0 & 2.4 & 65.8 & 14.4 & 0.59 \\
\hline 30 & Okayama & 3 & 34.68 & 5.5 & 16.5 & 1.9 & 66.6 & 14.3 & 0.63 \\
\hline 31 & Osaka & 1 & 34.68 & 5.5 & 17.4 & 1.9 & 63.4 & 14.4 & 0.62 \\
\hline 32 & Nara & 90 & 34.67 & 4.9 & 15.5 & 1.0 & 72.5 & 13.7 & 0.62 \\
\hline 33 & Hiroshima & 4 & 34.39 & 5.5 & 16.8 & 2.0 & 67.4 & 14.4 & 0.67 \\
\hline 34 & Takamatsu & 34 & 34.31 & 5.6 & 16.8 & 1.8 & 67.1 & 14.5 & 0.66 \\
\hline 35 & Wakayama & 14 & 34.22 & 5.7 & 17.1 & 2.2 & 65.5 & 14.7 & 0.64 \\
\hline 36 & Yamaguchi & 5 & 34.16 & 5.1 & 16.1 & 1.3 & 72.5 & 14.0 & 0.72 \\
\hline 37 & Tokushima & 2 & 34.06 & 5.7 & 17.0 & 2.2 & 66.8 & 14.7 & 0.63 \\
\hline 38 & Shizuoka & 14 & 34.05 & 5.9 & 16.9 & 1.5 & 68.0 & 14.7 & 0.61 \\
\hline 39 & Matsuyama & 41 & 33.84 & 5.5 & 16.9 & 1.4 & 66.8 & 14.5 & 0.69 \\
\hline 40 & Fukuoka & 3 & 33.58 & 5.1 & 17.5 & 1.8 & 67.6 & 14.1 & 0.71 \\
\hline 41 & Kochi & 1 & 33.56 & 5.9 & 17.5 & 1.3 & 68.5 & 14.9 & 0.69 \\
\hline 42 & Oita & 5 & 33.23 & 5.4 & 16.9 & 1.8 & 69.0 & 14.5 & 0.70 \\
\hline 43 & Saga & 3 & 33.07 & 5.4 & 17.1 & 2.4 & 69.9 & 14.4 & 0.73 \\
\hline 44 & Kumamoto & 15 & 32.81 & 5.4 & 17.4 & 1.5 & 70.1 & 14.6 & 0.76 \\
\hline 45 & Nagasaki & 7 & 32.73 & 5.1 & 17.6 & 1.6 & 70.3 & 14.2 & 0.77 \\
\hline 46 & Miyazaki & 9 & 31.93 & 5.8 & 18.0 & 2.0 & 73.0 & 15.0 & 0.86 \\
\hline 47 & Kagoshima & 4 & 31.55 & 5.3 & 19.0 & 1.9 & 69.8 & 14.6 & 0.86 \\
\hline 48 & Naha & 51 & 26.21 & 4.7 & 23.5 & 3.2 & 73.1 & 14.6 & 1.62 \\
\hline & Average $=$ & & & 5.2 & 15.4 & 1.9 & 69.5 & 13.8 & 0.6 \\
\hline
\end{tabular}

$\mathrm{n}$, measured sunshine hours; $T_{A v e}$, average air temperature; $\mathrm{u}_{2}$, measured wind speed; $R H$ measured relative humidity; $R_{S}$ solar radiation estimated with sunshine hours; $e_{\mathrm{a}}$, actual vapour pressure estimated with relative humidity. 
assessed using RMSE, Eq. 7. The RMSE is the square root of the variance of the residuals. It indicates the absolute fit of the model to the data-how close the observed data points are to the model's predicted values. RMSE is one of the three statistics which are used in linear regression to evaluate model fit.

$$
\operatorname{RMSE}_{(\text {Alt })}=\sqrt{\frac{1}{m} \sum_{i=1}^{m}\left(E T_{0(A l t) i}-E T_{0(s t) i}\right)^{2}}
$$

where $R M S E_{(\mathrm{Alt})}$ is the root mean square error $\left(\mathrm{mm} \mathrm{d}^{-1}\right), E T_{0}(\mathrm{St})$ is the correct reference evapotranspiration calculated using measured data $\left(\mathrm{mm} \mathrm{d}^{-1}\right), E T_{0 \text { (Alt) }}$ is the reference evapotranspiration calculated using alternative data $\left(\mathrm{mm} \mathrm{d}^{-1}\right), i$ is the suffix of each data point and $m$ is the total number of data points. In this paper, an $m$ of 360 was applied as an example that includes 12 months per year for 30 years.

The error propagation approach is designed to quantify the effect of variables' uncertainty on the error of a function to provide an accurate estimation of a function's error. When the $E T_{0}$ by FAO$56 \mathrm{PM}$ is estimated with alternative data, the error of the alternative data should be propagated to the error of $E T_{0}$. This is because the resulting output is a function of the input (Gerard, 1998). Therefore, in this study, obtaining the error of $E T_{0}$ using this approach, given as Eq. 8, was attempted. The approach consists of two components, in which the slope of the function is the derivative of $E T_{0}$ with respect to the variables. To calculate the slope, Eq. 1 is transformed into Eq. 9. In Eq. 9, components such as $R_{\mathrm{s}}, e_{\mathrm{a}}$ and $u_{2}$ are independent variables, while $a, b, c, d, f$ and $h$ do not include $R_{\mathrm{S},} e_{\mathrm{a}}$ nor $u_{2}$. The first and second components in Eq. 8 are given by Eq. 10 and 11, respectively.

$$
\begin{aligned}
& \Delta E T_{0(A l t)}=\left(\frac{\Delta E T_{0}}{\Delta x}\right) \times \Delta x \\
& E T_{0}=\frac{c R_{s}-\left(d-e \sqrt{e_{a}}\right)\left(f R_{s}-g\right)+h u_{2}\left(e_{s}-e_{a}\right)}{a+b u_{2}} \\
& \frac{\Delta E T_{0}}{\Delta x}=\sqrt{\frac{1}{m} \sum_{i=1}^{m}\left(\frac{\partial E T_{0}}{\partial x}\right)_{i}^{2}}
\end{aligned}
$$

$\Delta x_{(A l t)}=\sqrt{\frac{1}{m} \sum_{i=1}^{m}\left(x_{(s t) i}-x_{(A l t) i}\right)^{2}}$

where $a$ is given by $\Delta+\gamma, b$ is given by $0.34 \gamma, c$ is given by $0.408 \Delta(1-a), d$ is given by $0.34 \times 0.408 \Delta \sigma\left(T_{\max }+T_{\min }\right) \div 2$, $e$ is given by $0.14 \times 0.408 \Delta \sigma\left(T_{\max }+T_{\min }\right), 2, f$ is given by $1.35 \div R_{\mathrm{so}}$, $g$ is equivalent to $0.35, h$ is given by $900 \gamma \div\left(T_{\text {ave }}+233\right), \Delta E T_{0}$ is the average error of reference evapotranspiration $\left(\mathrm{mm} \mathrm{d}^{-1}\right), x$ is the independent variable ( $x$ can be $R_{\mathrm{s}}, e_{\mathrm{a}}$ or $u_{2}$ ), $\Delta x$ (Alt) is the order of the difference between the measured correct data $x_{(\mathrm{st})}$ and the alternative variable $x_{\text {(Alt) }}, i$ is the suffix of each data point and $m$ is the total number of data points.

\section{Results}

\section{Validity of $E T_{0}$ with Alternative data}

In order to assess the validity of the alternative data in $E T_{0}$ estimation, the FAO-56 PM equation was calculated with both sets of data, measured and alternative, in all study locations. The average estimation of $E T_{0(\mathrm{st})}$ and those of the $E T_{0(R \mathrm{~s})}, E T_{0(e \mathrm{a})}$ and $E T_{0(u 2)}$ are shown in Figure 2. The highest value was yielded by $E T_{0(R \mathrm{~s})}$ and followed by $E T_{0(e a)}$ and $E T_{0(u 2)}$, respectively in the second and third positions.

The relationship between $E T_{0(\mathrm{st})}$ and the models were significant, as $E T_{0(u 2)}$ had the strongest relationship ( $a=0.97$ and $R^{2}=$ $0.97)$, while $E T_{0(e a)}$ and $E T_{0(R s)}$ ranked second and third, respectively, Table 2.

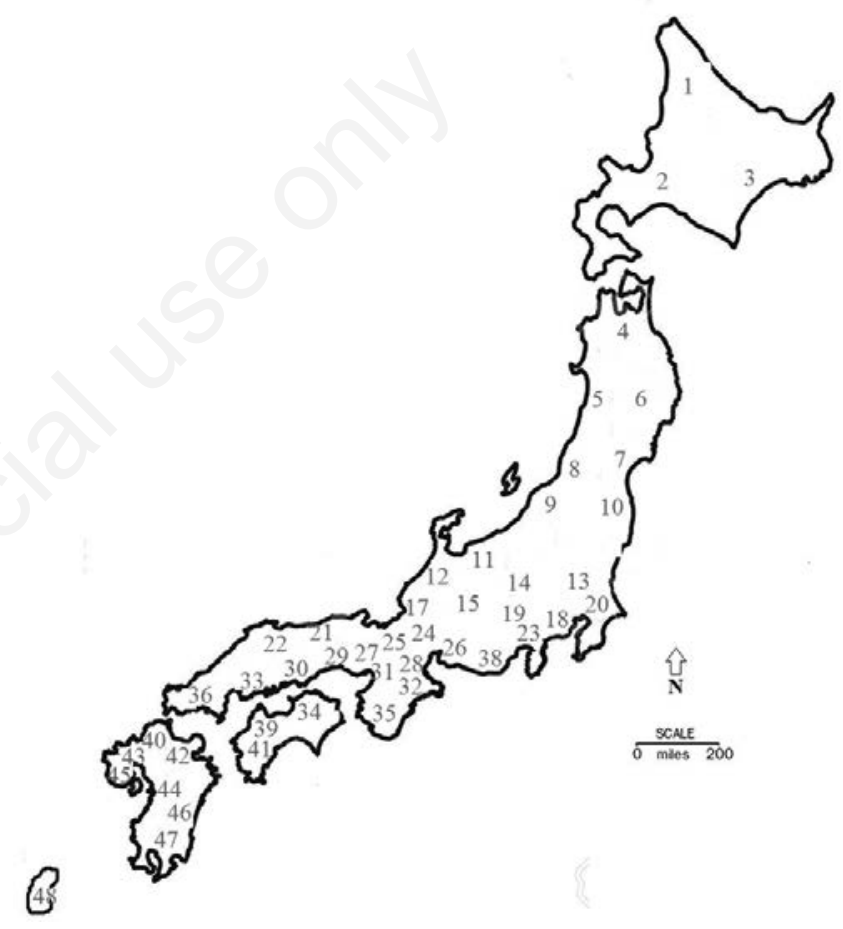

Figure 1. Map of Japan with the study's locations marked from 1-48.

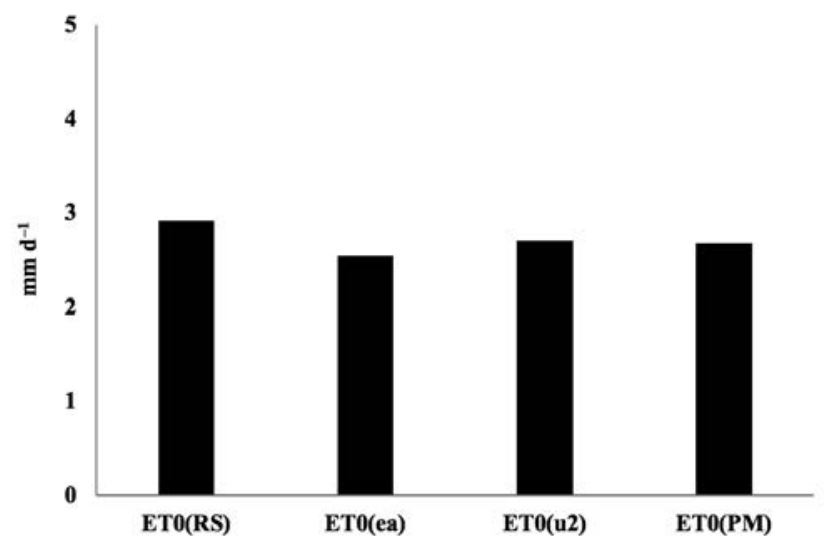

Figure 2. 30-year average estimation of $E T_{0(\mathrm{st})}$ and $E T_{0}$ estimated with alternative data. 
The agreement between $E T_{0 \text { (st) }}$ and the models was confirmed using $R M S E$ and $\triangle E T_{0}$, as depicted in Figure 3. The highest average $R M S E$ values were from $R M S E_{(R \mathrm{~s})}\left(0.34 \mathrm{~mm} \mathrm{~d}^{-1}\right)$ followed by $\operatorname{RMSE}_{(e \mathrm{a})}\left(0.20 \mathrm{~mm} \mathrm{~d}^{-1}\right)$ and $\operatorname{RMSE}_{(u 2)}\left(0.13 \mathrm{~mm} \mathrm{~d}^{-1}\right)$.

\section{Relationship between $R M S E_{(\mathrm{Alt})}$ and $\triangle E T_{0(\mathrm{Alt})}$}

The relationship between $R M S E_{(\text {Alt })}$ and $\triangle E T_{0(\mathrm{Alt})}$ is depicted at Figures 4-6. Figure 4 shows plots of $R M S E_{(R \mathrm{~s})}$ versus $\Delta E T_{0(R \mathrm{~s})}$. The values of $R^{2}=0.96$ and $k=0.92$ indicate a significant relationship with good proportionality among them. The plots of $R M S E_{(e a)}$ versus $\Delta E T_{0(e a)}$ demonstrate a significantly strong relationship and proportionality between them, with an $R^{2}$ value of 0.94 and $k=$ 0.92 , as shown in Figure 5. Figure 6 depicts the plots of $R M S E_{(u 2)}$

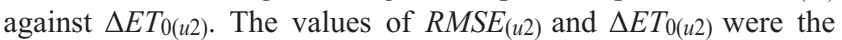
smallest. On the other hand, the values of $R^{2}=0.96$ and the proportionality coefficient $k=0.94$ confirm the best proportionality out of the cases studied.

\section{Error formation in $E T_{0}$}

The values shown at Table 3 relate to the derivative of $E T_{0}$ with respect to the variables (slope) and the variable's uncertainty. In the cases of $R_{\mathrm{S}}$ and $u_{2}$, slope is larger compared to the variables' uncertainty, while in the case of $e_{\mathrm{a}}$ it is smaller.

\section{Discussion}

The applicability of the error propagation approach for estimating $R M S E$ was examined using the data from 48 different locations for 360 months in Japan. The results confirmed that this is a good choice for predicting RMSE when confirming the validity of the alternative data in a region.

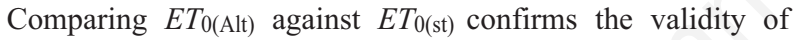
$E T_{0(\mathrm{Alt})}$ at Figure 2. $E T_{0(R \mathrm{~s})}$ was the largest among the alternatives compared to the $E T_{0(\mathrm{st})}$. On the other hand, the $R M S E_{(\mathrm{Rs})}$ and $\triangle E T_{0(R \mathrm{~s})}$ had the largest values, showing weaker agreement between $E T_{0(R \mathrm{~s})}$ and $E T_{0(\mathrm{st})}$ in Figure 3 compared to $E T_{0(u 2)}$ and $E T_{0(R \mathrm{~s})}$. The best agreement was obtained between $E T_{0(u 2)}$ and $E T_{0(s t)}$, shown in Figure 2. A comparison of $R M S E_{(u 2)}$ and $\Delta E T_{0(u 2)}$ was the lowest and very close to each other. Confirming agreement between the estimations is difficult without using $E T_{0(\mathrm{st})}$. By con-

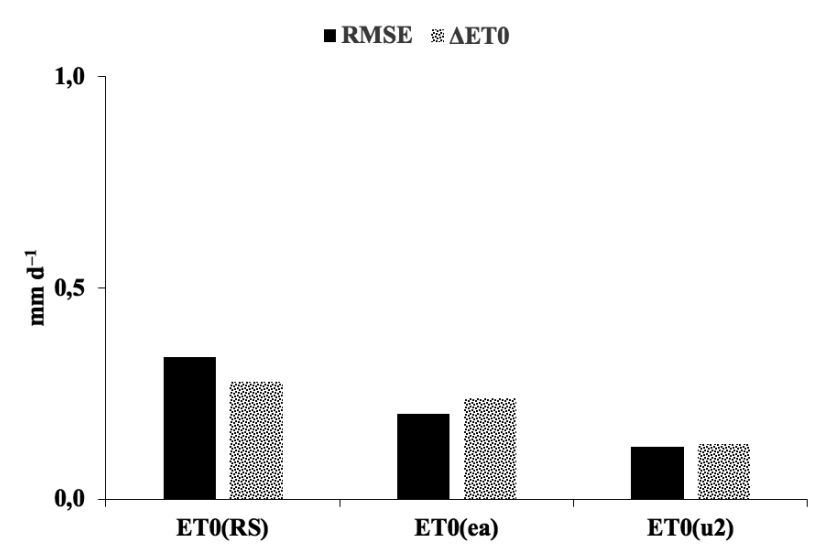

Figure 3. $R M S E$ and $\triangle E T_{0}$ for $E T_{0}$ estimated with alternative data.

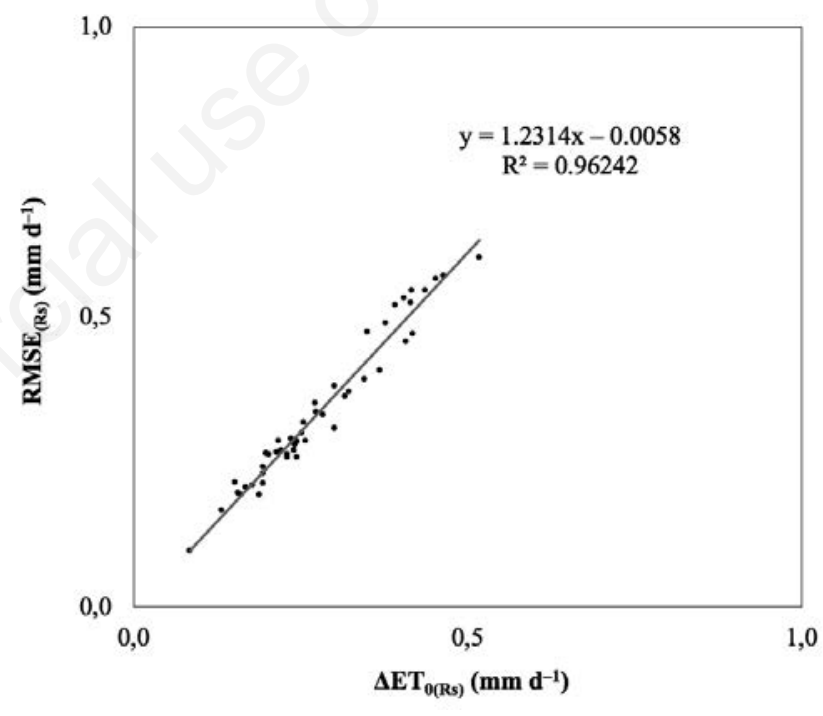

Figure 4. Relationship between $R M S E_{(R s)}$ and $\triangle E T_{0(R s)}$.

Table 2. Proportionality coefficient and the coefficient of determination between the correct reference evapotranspiration and those estimated with alternative data.

\begin{tabular}{|c|c|c|c|c|c|c|}
\hline \multirow[t]{2}{*}{ Station } & \multicolumn{2}{|c|}{$E T_{0}(R s)$} & \multicolumn{2}{|c|}{$E T_{0}(e a)$} & \multicolumn{2}{|c|}{$E T_{0(u 2)}$} \\
\hline & $b$ & $R^{2}$ & $b$ & $R^{2}$ & $b$ & $R^{2}$ \\
\hline 1 & 1.01 & 0.98 & 0.93 & 0.93 & 0.96 & 0.98 \\
\hline 2 & 1.09 & 0.97 & 1.06 & 0.98 & 0.97 & 0.98 \\
\hline 3 & 1.09 & 0.98 & 0.93 & 0.99 & 0.99 & 0.99 \\
\hline : & : & : & : & : & : & : \\
\hline$:$ & : & $:$ & $:$ & $:$ & : & : \\
\hline 46 & 1.06 & 0.96 & 0.99 & 0.99 & 0.99 & 0.99 \\
\hline 47 & 1.04 & 0.97 & 0.93 & 0.96 & 0.99 & 0.94 \\
\hline 48 & 0.94 & 0.88 & 0.83 & 0.87 & 0.92 & 0.96 \\
\hline Average & 1.04 & 0.96 & 0.95 & 0.95 & 0.97 & 0.97 \\
\hline
\end{tabular}

$E T_{0(R s)}$, reference evapotranspiration estimated with alternative solar radiation data; $E T_{0(e a)}$, reference evapotranspiration estimated with alternative, actual vapour pressure data; $E T_{0(u 2)}$, reference evapotranspiration estimated with alternative wind speed data; $b$ is slop; $R^{2}$ is determination coefficient. 
sidering $E T_{0 \text { (st) }}$ the results for the $E T_{0 \text { (Alt) }}$ estimation demonstrate the relationship shown at Eq. 12. The same relationship existed in

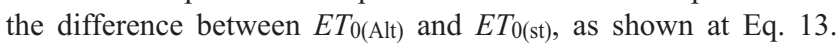
Interestingly, a similar relationship could be confirmed in the case

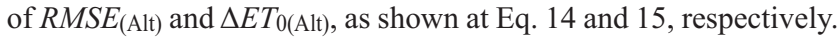
From this result, $\Delta E T_{0 \text { (Alt) }}$ can be expected to be proportional to $R M S E_{(\mathrm{Alt}) \text {. }}$

$$
E T_{0(R s)}>E T_{0(u 2)}>E T_{0(s t)}>E T_{0(e a)}
$$

$$
\left|E T_{0\left(R_{s}\right)}-E T_{0(S t)}\right|>\left|E T_{0\left(e_{a}\right)}-E T_{0(S t)}\right|>\left|E T_{0\left(u_{2}\right)}-E T_{0(S t)}\right|
$$

$$
\operatorname{RMSE}_{\left(R_{s}\right)}>\operatorname{RMSE}\left(e_{a}\right)>\operatorname{RMSE}\left(u_{2}\right)
$$

$$
\Delta E T_{0\left(R_{s}\right)}>\Delta E T_{0\left(e_{a}\right)}>\Delta E T_{0\left(u_{2}\right)}
$$

The order of the difference of $\left|R M S E_{(R \mathrm{~s})}-\triangle E T_{0(R \mathrm{~s})}\right|$ was the largest followed by those of $\left|R M S E_{(e a)}-\triangle E T_{0(e a)}\right|$ and $\mid R M S E_{(u 2)}-$ $\triangle E T_{0(u 2)}$, as shown in Eq. 16.

$$
\left.\left|R M S E_{\left(R_{s}\right)}-\Delta E T_{0\left(R_{s}\right)}\right|>\mid R M S E_{\left(e_{a}\right)}-\Delta E T_{0\left(e_{a}\right)}\right)>\left|R M S E_{\left(u_{2}\right)}-\Delta E T_{0\left(u_{2}\right)}\right|
$$

The order of the difference between $R M S E_{(u 2)}$ and $\Delta E T_{0(u 2)}$ was very small, as shown at Figure 3. However, the difference was slightly higher in the case of $R M S E_{(R \mathrm{~s})}-\triangle E T_{0(R \mathrm{~s})}$ and $R M S E_{(e a)}-$ $\triangle E T_{0(e a)}$. At Figures 4 to 6 , they show high $R^{2}$ and each plot seems to be located on the solid line of proportionality. This kind of proportionality was un-expected from each equation. Based on this experience, we suggest that $R M S E$ will be expressed as $R M S E_{(R s)}$ $=1.21 \Delta E T_{0(R \mathrm{~s})}$ and $\operatorname{RMSE}_{(e a)}=0.87 \Delta E T_{0(e a)}$, shown at Figures 4 and 5 , respectively. From the results at Figures 4 to 6 , it will be possible for us to predict $R M S E$ as $\triangle E T_{0}$ in the range of almost $12 \%$ error in the three cases, shown at Equations. 17 to 19 . These kinds of equations may be helpful for confirming the validity of $E T_{0 \text { (Alt) }}$ in those areas where the RMSE is difficult to estimate due to the lack of all kinds of measured data.

$$
\begin{array}{ll}
\operatorname{RMSE}_{\left(R_{s}\right)}=1.21 \Delta E T_{0\left(R_{s}\right)} & \left(R^{2}=0.96\right) \\
\operatorname{RMSE}_{\left(e_{a}\right)}=0.87 \Delta E T_{0\left(e_{a}\right)} & \left(R^{2}=0.94\right) \\
\operatorname{RMSE}_{\left(u_{2}\right)}=0.94 \Delta E T_{0\left(u_{2}\right)} & \left(R^{2}=0.96\right)
\end{array}
$$

The values shown in Table 3 indicate that the error in the $E T_{0}$ estimation is related to two components. The first is the derivative of $E T_{0}$ with respect to the variables, which relates to the structure of the $E T_{0}$ equation. Any change in the structure of the equation causes a change in slope value. By improving the structure of the equation, the value of the slope will change; smaller values reduce the error in the $E T_{0}$ estimation. The second component that con-

\begin{tabular}{|c|c|c|c|c|c|}
\hline & & $\Delta E T_{0 / \Delta \mathrm{x}}$ & & $\Delta x$ & $\Delta E T_{0}$ \\
\hline$R_{S}$ & 3.02 & $\mathrm{~mm} \mathrm{~d}^{-1} / \mathrm{MJ} \mathrm{m}^{2} \mathrm{~d}^{-1}$ & 0.10 & $M J m^{2} d^{-1}$ & $0.29 \mathrm{~mm} \mathrm{~d}^{-1}$ \\
\hline$e_{a}$ & 0.16 & $\mathrm{~mm} \mathrm{~d}^{-1} / \mathrm{kPa}$ & 1.76 & $\mathrm{kPa}$ & $0.28 \mathrm{~mm} \mathrm{~d}^{-1}$ \\
\hline$u_{2}$ & 0.55 & $\mathrm{~mm} \mathrm{~d}^{-1} / \mathrm{m} \mathrm{s}^{-1}$ & 0.28 & $\mathrm{~m} \mathrm{~s}^{-1}$ & $0.15 \mathrm{~mm} \mathrm{~d}^{-1}$ \\
\hline
\end{tabular}
tributes to the error of $E T_{0}$ is the variables' uncertainty. This kind of uncertainty relates to the methods through which they are obtained. The methods presented by FAO to estimate the missing data can be improved. By improving the methods, it would be possible to estimate the missing variables with less uncertainty.
Table 3. The average values corresponding to the components of Eq. 8.

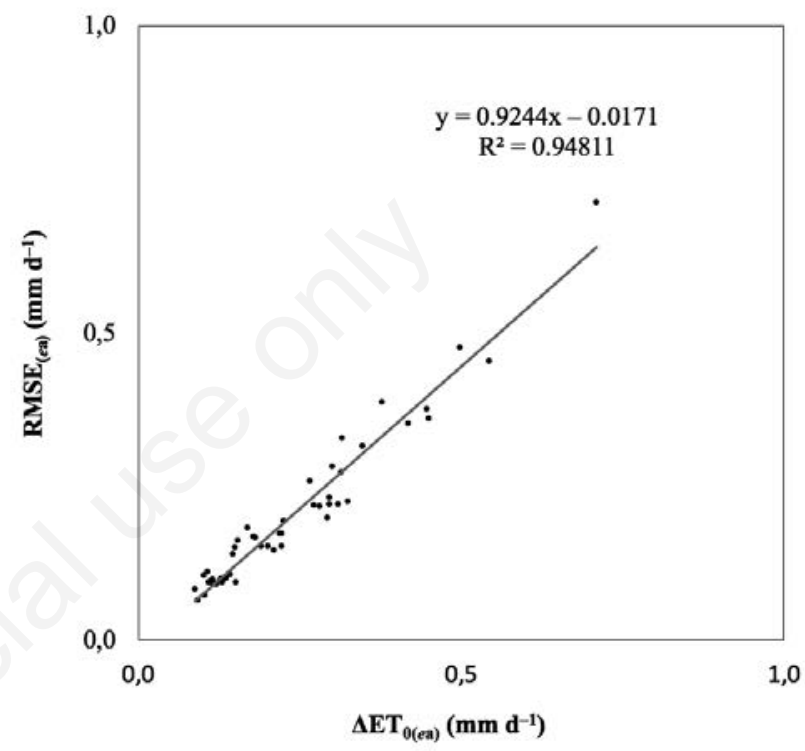

Figure 5. Relationship between $R M S E_{(e a)}$ and $\triangle E T_{0(e a)}$.

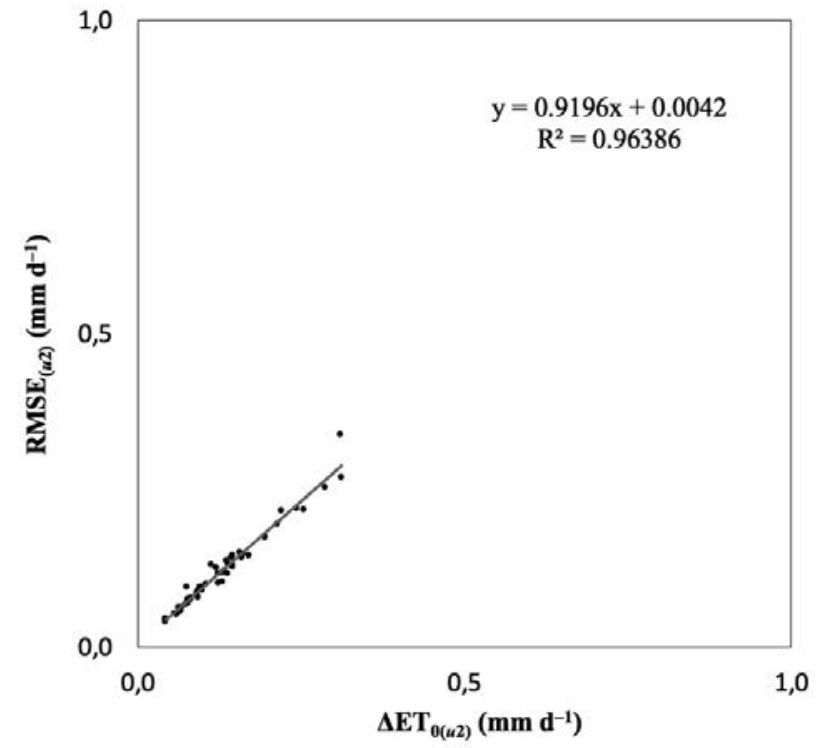

Figure 6. Relationship between $\operatorname{RMSE}_{(u 2)}$ and $\Delta E T_{0(u 2)}$. 


\section{Conclusions}

In this study, considering the hypothesis, the error propagation approach was applied first for estimating the RMSE of the $E T_{0}$ that was calculated with alternative data as recommended by FAO, and second for examining the mechanise of error formation in the $E T_{0}$ estimation. From the results, it was confirmed that RMSE is proportional to $\triangle E T_{0}$ with a proportionality coefficient close to unity and a regression coefficient of above 0.93 in three cases. Furthermore, it was found that the error in the $E T_{0}$ estimation when calculated with alternative data was related to two components: the variables' uncertainty that comes from the alternative data and the combination of the variables in the equation i.e. the derivation of the function with respect to the variables, known as slope of the function.

The finding of this study is helpful for accurate calculation of irrigation water depth, especially when some measured data are missing. As the $E T_{0}$ is the main component when calculating the irrigation water depth, It is expected that errors in the $E T_{0}$ calculation, especially in areas facing data scarcity, will be reduced by considering sensitivity of the $E T_{0}$ equation to meteorological data obtained using alternative proposals. For instance, in this study the calculation of $E T_{0}$ was found highly sensitive to the alternative data of $e_{\mathrm{a}}$ and $R_{\mathrm{S}}$, the errors yielded high when they were used in the calculation. Such information help the irrigators to take care when using alternative data.

\section{References}

Alexandris S., Kerkides P., Liakatas A. 2005. Daily reference evapotranspiration estimates by the "Copais" approach. Agricul. Water Manage. 82:371-86.

Allen R.G., Pereira-Luis S., Dirk R., Martin S. 1998. FAO Irrigation and drainage paper No. 56. Rome. FAO. 56:97-156.

Chiew F., Kamaladasa N., Malano H.M., McMahon T.A. 1995.
Penman-Monteith, FAO-24 reference crop evapotranspiration and class-A pan data in Australia. Agricult. Water Manage. 28:9-21.

Cordova M., Galo C.R., Patricio C., Bradford W., Rolando C. 2015. Evaluation of the Penman-Monteith (FAO-56 PM) method for calculating reference evapotranspiration using supplementary data application to the wet Páramo of Ecuador. J. Mt. Res. Dev. 35:230-9.

Droogers P., Allen R.G. 2002. Estimating reference evapotranspiration under inaccurate data conditions. J. Irrig. Drain. Syst. 16:33-45.

Gavilán P., Lorite I.J., Tornero S., Berengena J. 2006. Regional calibration of Hargreaves equation for estimating reference evapotranspiration in a semiarid environment. Agricult. Water Manage. 81:257-81.

Gerard B.M.H. 1998. Error propagation in environmental modeling with GIS. CRC Press, Boca raton, FL, USA.

Hargreaves G.H., Samani Z.A. 1985. Reference crop evapotranspiration from temperature. J. Appl. Eng. Agric. 1:96-9.

Jabloun M.D., Sahli A. 2008. Evaluation of FAO-56 methodology for estimating reference evapotranspiration using limited climatic data: application to Tunisia. Agricul. Water Manage. 95:707-15.

Kimbal J.S., Running S.W., Nemani R. 1997. An improved method for estimating surface humidity from daily minimum temperature. Agr. Forest Meteorol. 85:87-98.

Pereira A.R., Pruitt W.O. 2004. Adaptation of the Thornthwaite scheme for estimating daily reference evapotranspiration. Agricul. Water Manage. 66:251-7.

Popova Z., Milena K., Luis S.P. 2006. Validation of the FAO methodology for computing $\mathrm{ET}_{0}$ with supplementary data, Application to South Bulgaria. Irri. Drain. Eng. 55:201-5.

Sentelhas P.C., Terry J.G., Eduardo A.S. 2010. Evaluation of FAO Penman-Monteith and alternative methods for estimating reference evapotranspiration with missing data in southern Ontario, Canada. Agricul. Water Manage. 97:635-44. 